\title{
Shrimp-Paddy Conflict in the South-West Coastal Region of Bangladesh
}

\author{
Mohammed Ziaul Haider*, Rabeya Akter \\ Economics Discipline, Khulna University, Khulna, Bangladesh \\ Email address: \\ haidermz@yahoo.com (M. Z. Haider), rabeya.ku08@gmail.com (R. Akter) \\ ${ }^{*}$ Corresponding author
}

\section{To cite this article:}

Mohammed Ziaul Haider, Rabeya Akter. Shrimp-Paddy Conflict in the South-West Coastal Region of Bangladesh. International Journal of Agricultural Economics. Vol. 3, No. 1, 2018, pp. 9-13. doi: 10.11648/j.ijae.20180301.12

Received: November 30, 2017; Accepted: January 17, 2018; Published: February 5, 2018

\begin{abstract}
Shrimp cultivation is a comparatively new agricultural practice in the south-west coastal region of Bangladesh. The objective of this study is to analyze the costs and returns of shrimp and paddy cultivation for understanding the behavior of the farmers in the south-west coastal region of Bangladesh. This study compares cost and return of shrimp and paddy cultivation through collecting primary data from 60 randomly selected farmers from the study area. The derived economic benefit-cost ratio (BCR) of shrimp production is 1.67 and that of paddy production is 1.36 indicating that shrimp production is more profitable than paddy production from economic viewpoint. However, the BCR of shrimp production decreases to 1.04 while the associated external cost of land degradation is added in cost side. The ratio would further decrease to less than one if other indirect cost items such as health cost, loss in livestock, mangrove destruction and biodiversity losses are considered. Such results signal that shrimp production is not a profitable option from a society viewpoint. The study findings also indicate that cost of shrimp production increases and return from shrimp production decreases over the time period. The paddy farmers in the study area moved towards shrimp farming in the 1980s for getting short-run higher benefits. However, the unfavorable changes in cost and production and lower BCR from society viewpoint explain the recent reverse move of farmers from shrimp cultivation towards paddy production for re-solving shrimp-paddy conflict in the study area. Shrimp expansion led salinity intrusion creates constraints in the move in some cases. An active cooperation of government through enforcing associated rules and regulations might be helpful for the farmers of the south-west coastal region to protect their livelihood and efficiently re-solve the shrimp-paddy conflict.
\end{abstract}

Keywords: Shrimp, Paddy, Benefit-Cost Ratio, Social Cost, South-West Coastal Region of Bangladesh

\section{Introduction}

Bangladesh is an agro-based country. Agriculture sector plays a significant role in the economy of the country. This sector offers job opportunity mainly to rural poor. Almost 80 percent people of the country are involved in agriculture sector for their livelihood. The country has about 2.83 million hectares of land for paddy production [1]. On the other hand, shrimp cultivation is a comparatively new agricultural practice in the south-west coastal region of the country. According to the study [2], about 4 million hectares open inland water body, about 4.3 million hectares closed water body and 710 kilometer coast lines are available in the country for aquaculture.

Salinity is an integral part of both soil and water. Like other components of soil and water, a specific ratio of salinity is required to keep balance in environment. An increase in the ratio creates negative impacts. This salinity originates from the shrimp cultivation by retaining tidal water. Because of this salinity, the productivity of adjacent paddy fields decreases. In addition to such a decrease in paddy productivity, shrimp cultivation exerts adverse impacts on the environment.

A proper recognition of the said negative impacts of shrimp cultivation might encourage farmers to think about alternatives of shrimp farming. A field level investigation in the south-west coastal region of Bangladesh reveals that cultivation of shrimp has been squeezing since last several years. The farmers are going back to the traditional practice of paddy cultivation in agricultural fields. The aim of this 
study is to analyze the associated costs and returns of shrimp and paddy cultivation for understanding the behavior of the farmers in the south-west coastal region of Bangladesh.

\section{Material and Methods}

Historically paddy cultivation is the main and traditional occupation of farmers in Bangladesh. Farmers have started shrimp cultivation in addition to paddy in the farming fields since 1980s. Several studies [2-6] have tried to compare shrimp and paddy sectors on the basis of Benefit-Cost Ratio (BCR). An intensive review of literature reveals that most of the available studies have captured only the direct costs and benefits [6-12]. However, some other studies have tried to capture some of the indirect costs [3; 13-15]. Following the methodology of the said literatures, this study attempts to address the shrimp-paddy conflict in the south-west coastal region of Bangladesh.

This study tries to analyze the trend and logic for conversion of shrimp farm into paddy field. It compares the economic cost and return of shrimp production with those of paddy production. In addition to economic costs and returns, the social and environmental consequences are also considered in this study and an attempt has been made to internalize those social and environmental issues. Finally, the concept of BCR is applied to draw a conclusion.

For calculating the economic cost of shrimp production, this study considers four elements: a) cost of land (or lease cost $)^{1}$, b) labor cost, c) fry cost and d) feeding cost for shrimp. All these costs are measured in US\$. To calculate the return from shrimp production, total shrimp production (in $\mathrm{kg}$ ) and average market price (US\$ per $\mathrm{kg}$ ) are considered. Similarly, for calculating the economic cost of paddy production, this study considers five elements: a) cost of land (or lease cost), b) labor cost, c) seed cost, d) fertilizer cost and e) insecticide cost for paddy production. All these costs are measured in US\$. To calculate the return from paddy production, total paddy production (in $\mathrm{kg}$ ) and average market price (US\$ per $\mathrm{kg}$ ) are considered.

After calculating the economic cost and return of shrimp and paddy production, Net Revenue (NR) and BCR have been calculated. Following the study of [6], the NR and BCR of shrimp and paddy production have been calculated in this study as per equation 1 .

$$
N R=G R-T C ; B C R=G R / T C
$$

where, $\mathrm{NR}=$ Net Revenue; $\mathrm{GR}=\mathrm{Gross}$ Revenue; $\mathrm{TC}=$ Total Cost; $\mathrm{BCR}=$ Benefit-Cost Ratio

A positive NR indicates profit, while a negative NR indicates loss. A comparison between the values of NR of shrimp and paddy production helps to understand the trend of conversion between shrimp and paddy production and hence the shrimp-paddy conflict in the study area. Similarly, BCR value also helps to explain the said conversion as well as the

1 For land owner farmers, the lease cost of the adjacent land is considered as land cost. conflict between shrimp and paddy production. A BCR value of greater than one indicates profit, while a BCR value of less than one indicates loss. Such NR and BCR values help to reach a logical conclusion regarding the study topic, conflict between shrimp and paddy production.

To extend the discussion beyond economic costs and returns associated with shrimp and paddy production, the environmental consequences of shrimp farming has been internalized in the calculation. An intensive literature survey identifies several environmental impacts of shrimp production. A careful consideration of such environmental impacts (i.e. indirect costs) of shrimp farming helps to internalize the adverse effects of shrimp cultivation, which ultimately helps to explain the conflict between shrimp and paddy production. It also helps to justify the new trend in the agricultural sector of the study area.

The main objective of this study is to compare the shrimp and paddy production to explain the conflict between these two in the study area. It collects farm-level data from randomly selected 60 farmers of Dacope upazilla ${ }^{2}$ under Khulna district of Bangladesh. It follows a stratified random sampling procedure where shrimp and paddy farmers are the two strata. The surveyed sample farmers include 30 shrimp and 30 paddy cultivators. A structured questionnaire is used to collect primary data. Some secondary information is also used to address the study objectives.

\section{Results and Discussion}

\subsection{Economic Cost of Production}

Table 1 portrays the economic cost of shrimp and paddy production. The calculation considers land, labor, fry and feeding costs for shrimp production and land, labor, seed, fertilizer and insecticide costs for paddy production. According to field level data, cost of shrimp production increases over the time period. However, cost of paddy production remains almost same over the considered time period. The results also indicate that mean cost of shrimp production per acre is more than double of paddy production (Table 1).

Table 1. Economic cost of production.

\begin{tabular}{lllll}
\hline \multirow{2}{*}{ Production cost (US\$/acre) } & \multicolumn{2}{l}{ Year } & \multirow{2}{*}{ Average } \\
\cline { 2 - 4 } & $\mathbf{2 0 0 6}$ & $\mathbf{2 0 0 7}$ & $\mathbf{2 0 0 8}$ & \\
\hline Shrimp $(\mathrm{N}=30)$ & 321 & 333 & 376 & 343 \\
Paddy $(\mathrm{N}=30)$ & 164 & 169 & 169 & 167 \\
\hline
\end{tabular}

Source: Field Survey, 2012.

\subsection{Economic Return from Production}

The calculation of economic return from shrimp and paddy production requires data of price and corresponding quantity. This study considers average market price data and average production data collected from the field survey on the sample

2Total area of Dacope upazilla is around 991.58 sq. $\mathrm{km}$ having nine unions. Number of farmers in the upazilla is around 24,000 
farmers. According to Table 2, the return from shrimp production is lower in the year 2008 compared to that of year 2007. However, the return from paddy production is higher in the year 2008 compared to other two years. The mean return from shrimp production is about 2.5 times higher than that of paddy production.

Table 2. Economic return from production.

\begin{tabular}{lllll}
\hline \multirow{2}{*}{ Items } & \multicolumn{2}{c}{ Year } & & \multirow{2}{*}{ Average } \\
\cline { 2 - 4 } & $\mathbf{2 0 0 6}$ & $\mathbf{2 0 0 7}$ & $\mathbf{2 0 0 8}$ & \\
\hline Average price of shrimp (US\$/kg) & 4.51 & 4.51 & 5.15 & 4.72 \\
Average price of paddy (US\$/kg) & 0.26 & 0.26 & 0.27 & 0.26 \\
Shrimp production (kg/acre) & 123 & 131 & 111 & 122 \\
Paddy production (kg/acre) & 880 & 880 & 840 & 880 \\
Shrimp production (US\$/acre) & 552 & 592 & 573 & 572 \\
Paddy production (US\$/acre) & 225 & 227 & 231 & 228 \\
\hline
\end{tabular}

Source: Field Survey, 2012.

N. B.: N=30 (Shrimp farmers), N=30 (Paddy farmers).

\subsection{Benefit-Cost Ratio (Economic)}

Calculation of the BCR of shrimp and paddy production includes Total Cost (in US\$/acre) and Gross Revenue (in US\$/acre). Table 3 illustrates the BCR and NR of shrimp and paddy production. According to the survey findings, both Gross Revenue (GR) and Total Cost (TC) of shrimp production are higher than that of paddy production. The NR from shrimp production is also higher than that of paddy production (Table 3 ). The calculated values of BCR for both the shrimp and paddy productions are greater than one and the value is comparatively higher for shrimp production than that for paddy production.

Table 3. Economic analysis of production.

\begin{tabular}{llll}
\hline Economic indicators & Unit & Shrimp & Paddy \\
\hline Gross Revenue (GR) & US\$/acre/Year & 572 & 228 \\
Total Cost (TC) & US\$/acre/Year & 343 & 167 \\
Net Revenue (NR) $=$ GR-TC & US\$/acre/Year & 229 & 61 \\
Benefit-Cost Ratio $=$ GR/TC & Ratio & 1.67 & 1.36 \\
\hline
\end{tabular}

Source: Field Survey, 2012.

N. B.: $\mathrm{N}=30$ (Shrimp farmers), $\mathrm{N}=30$ (Paddy farmers).

\subsection{Social Benefit-Cost Ratio}

In addition to production cost, there are many other unaccounted and unaddressed costs of shrimp production, which have negative impacts on soil productivity, human health, biodiversity, watersheds and society. For example, land degradation, mangrove destruction, biodiversity loss, health hazard and change in hydrology of watershed are notable in this regard. Among these, the costs of land degradation due to shrimp culture in Bangladesh are captured in this study. Introduction of shrimp culture in the paddy field hampers paddy production. Another cost of land degradation is restoration cost [3]. The restoration system requires some technology and cost of this technology is called reclamation cost of shrimp production. The main elements of the technology involve: a) installation of deep drains to lower the water table, b) leaching of salinized areas requiring the application of non-saline water in amounts considerably in excess of the irrigation requirement and c) treatment of sodic soil with gypsum [3].

This study considers both primary and secondary information to calculate social BCR of shrimp production. Calculations of direct costs and benefits of shrimp production consider primary data collected from the field survey in 2012. For indirect cost of shrimp production, this study considers secondary data. The study [3] assumes that land degradation arising from salinity due to shrimp culture in Bangladesh is of moderate degree: 45 percent loss in production of paddy per acre. According to the field survey findings, the production of paddy is $880 \mathrm{~kg}$ per acre (Table 2 ). Assuming that the field survey and secondary information are true, production loss is $396(=880 * 0.45) \mathrm{kg}$ Aman paddy per acre. As the average market price of Aman paddy is 0.26 US\$ per kg (Table 2), the monetary value of this production loss is 102US\$ per acre. Moreover, the study [3] assumes that the reclamation or restoration cost for degraded land in shrimp cultivating area of Bangladesh (except Chittagong) would be 30 million US\$ and estimated shrimp cultivated area coverage (except Chittagong) is $116 \quad\left(=145^{*} 0.80\right)$ thousand hectare. Therefore, the resulting reclamation or restoration cost is approximately 105US\$ per acre (Table 4).

Table 4. Social BCR of shrimp production.

\begin{tabular}{lll}
\hline Items & Unit & Value \\
\hline $\begin{array}{l}\text { Direct Costs of shrimp production } \\
\text { Total Cost of production }\end{array}$ & US\$/acre & 343 \\
Indirect Costs of shrimp production & & \\
Cost of production loss basis & US\$/acre & 102 \\
Restoration cost basis & US\$/acre & 105 \\
Total Cost (TC) & US\$/acre & 550 \\
Direct Benefits of shrimp production & & \\
Gross Revenue (GR) & US\$/acre & 572 \\
Net Revenue (NR $=$ GR - TC) & US\$/acre & 22 \\
Benefit-Cost Ratio (BCR $=$ GR/TC) & Ratio & 1.04 \\
\hline
\end{tabular}

Source: Authors' Compilation.

Adding direct and indirect costs generate a higher cost value and accordingly a lower NR value (Table 4) which signals a lower profit from shrimp cultivation. The calculated social BCR of shrimp production is 1.04 . Adding other indirect cost components, such as health cost, loss in livestock, mangrove destruction and loss of biodiversity (as described in [3] might generate a negative $\mathrm{NR}$ and less than one BCR value indicating loss in shrimp cultivation.

\section{Conclusions}

Paddy production is the traditional means of livelihood for a majority of the farmers of Bangladesh [16]. In contrast, shrimp production is a comparatively new practice in the country which has started its journey since 1980 s. It is a traditional aquaculture in south-west coastal Bangladesh [17]. A short-run lucrative profit of shrimp production attracts the attention of the farmers. They 
initially ignored the decrease in paddy productivity due to shrimp production.

The economic cost and return analysis show that the BCR of shrimp production is 1.67 and the BCR of paddy production is 1.36 (Table 3 ). However, the BCR of shrimp production including the costs of land degradation due to shrimp culture in paddy field is 1.04 (Table 4) which is very close to one and might decrease to less than one [18] after considering other unaccounted indirect costs. The environmental impact of shrimp production on land is very much hazardous. Shrimp production has negative externality on society. The external social cost of shrimp production falls upon other party rather than the shrimp producer. So, by considering economic and external costs and benefits of shrimp culture, it can be concluded that, the costs of shrimp production might be higher as compared to the benefits from it. The benefits of shrimp production are limited within export earnings and employment generation, whereas the costs of shrimp production are multidimensional.

The farmers in the study area have identified a gradual declining trend of shrimp production over the time period against a comparatively stable paddy production. Moreover, some farmers have realized the external and indirect costs of shrimp farming which are mostly unobserved, invisible and ignored. As a result, the farmers are again attempting to shift towards paddy production. However, the shrimp expansion led salinity intrusion creates constraints in the said shift in some cases. The farmers are handling the constraints and gradually moving back towards the traditional paddy production in the south-west coastal region of Bangladesh. An active cooperation of government through limiting shrimp cultivation in some selected saline areas and through enforcing associated rules and regulations might be helpful for the farmers of the south-west coastal region to protect their livelihood and efficiently re-solve the shrimp-paddy conflict.

\section{Acknowledgements}

The authors acknowledge to the survey respondents for providing valuable information. Acknowledgements are also due to Economics Discipline, Khulna University, Bangladesh for granting permission to conduct the study as a partial fulfillment of BSS (Hons.) degree. However, the views expressed in this paper are those of the authors and do not necessarily reflect the views of the respondents or of the concerned organization.

\section{References}

[1] Amin, A. R., \& Salauddin, M. (2008). Effect of inclusion of prawn and mola on water quality and rice production in prawn-fish-rice culture system. Turkish Journal of Fisheries and Aquatic Sciences, 8, 15-23.

[2] Barmon, B. K., Kondo, T., \& Osanami, F. (2003). Impact of rice-prawn gher farming on agricultural and household income in Bangladesh: A case study of Khulna district. Department of Agricultural Economics, Hokkaido University, Japan, 51-61.

[3] Bhattacharya, D., Rahman, M., \& Khatun, F. A. (1999). Environmental consequences of structural adjustment: Towards sustainable shrimp culture in Bangladesh. CPD Occasional Paper Series 2, Dhaka, Bangladesh.

[4] Shah, W. A., Phillips, M., Kamal, S., Jahan, I., \& Sarker, J. (2000). The economics of bagda shrimp (Penaeus Monodon) farming in coastal areas of Bangladesh. Grassroots Voice, 3 (1-2), 38-65.

[5] Ling, B. H., Leung, P. S., \& Shang, Y. C. (2001). Comparing Asian shrimp farming the Domestic Resource Cost (DRC) approach. In: Leung, P. S. and Sharma, K. K. (Eds.), Economic and Management of Shrimp and Carp Farming in Asia, Network of Aquaculture Centers in Asia-Pacific, Bangkok, Thailand.

[6] Hasanuzzaman, A. F. M., Rahman, M. A., \& Islam, S. S. (2011). Practice and economics of fresh water prawn farming in seasonally saline rice field in Bangladesh. Mesopotamian Journal of Marine Science, 26 (1), 69-78.

[7] Abedin J., \& Kabir K. (1999). Cost benefit analysis of gher system under Khulna areas before project intervention. Survey report prepared by Greater Options for Local Development through Aquaculture Project of CARE-Bangladesh.

[8] Abedin, J., Sarker, G., \& Hena, A. (1997). A cost benefit analysis of current gher farming system practices in Bagerhat district. Paper presented at the CARE Bangladesh aquaculture workshop, BARD, Comilla, Bangladesh.

[9] Ahmed, N., Demaine, H., \& Muir, J. F. (2008). Freshwater prawn farming in Bangladesh: history, present status and future prospects. Aquaculture Research, 39, 806-819.

[10] ATDP II. (2005). An evaluation of the Bangladesh agro-based industries and technology development project (ATDP II). Report submitted to United States Agency for International Development (USAID), Bangladesh.

[11] DTS. (2006). A pro-poor analysis of the shrimp sector in Bangladesh. Report prepared by Development \& Training Services, Inc. (DTS) for United States Agency for International Development (USAID) under Greater Access to Trade Expansion (GATE) project.

[12] Haque, A. K. E. (2004). Sanitary and phyto-sanitary barriers to trade and its impact on the environment - The case of shrimp farming in Bangladesh. Trade Knowledge Network (TKN) Paper.

[13] Bhattacharya, P., \& Ninan, K. N. (2009). Social cost-benefit analysis of scientific versus traditional shrimp farming: A case study from India. Paper prepared for presentation at the International Association of Agricultural Economists' 2009 Conference, Beijing, China.

[14] Bundell, K., \& Maybin, E. (1996). After the prawn rush - The human and environmental costs of commercial prawn farming. Christian Aid web page, Available at: www.christianaid.org.uk (accessed on 15 January, 2012).

[15] UNEP. (1999). Trade liberalisation and the environment Lessons learned from Bangladesh, Chile, India, Philippines, Romania and Uganda: A synthesis report. United Nations Environment Programme (UNEP), UNEP/99/7, United Nations, New York and Geneva. 
[16] Shelley, I. J., Takahashi-Nosaka, M., Kano-Nakata, M., Haque, M. S., \& Inukai, Y. (2016). Rice Cultivation in Bangladesh: Present Scenario, Problems, and Prospects, Journal of International Cooperation for Agricultural Development, 14, 20-29.

[17] Akber, M. A., Islam, M. A., Ahmed M., Rahman, M. M. \& Rahman. M. R. (2017). Changes of Shrimp Farming in
Southwest Coastal Bangladesh, Aquaculture International, 25 (5), 1883-1899.

[18] Haider, M. Z. (2015). Cost-Benefit Analysis of Shrimp Cultivation in the South-west Region of Bangladesh, International Journal of Environment and Sustainable Development, 14 (4), 315-331. 